\title{
STATIC AND FATIGUE CHARACTERIZATION OF NOMEX HONEYCOMB SANDWICH PANELS
}

\author{
KESKES BOUALEM ${ }^{*}$, Z. AZARI $^{2}$ \\ ${ }^{1}$ LMPA, Institut d'Optique et de Mécanique de Précision, Université de Setif Algerie. \\ keskes@univ-metz.fr, b_keskes@yahoo.fr \\ ${ }^{2}$ LABSC, ENIM, Université de Metz France cedex \\ azari@univ-metz.fr
}

Received: 04.01.2013, Accepted: 07.02.2013

doi: $10.5505 /$ pajes.2013.07279

*Corresponding author

\begin{abstract}
The main benefits of using the sandwich concept in structural components are the high stiffness, good fatigue resistance and low weight ratios. Recent advances in materials and construction techniques have resulted in further improvement and increased uniformity of the sandwich composite properties. In order to use these materials in different applications, the knowledge of simply their static properties alone is not sufficient but additional information on their fatigue properties and durability are required. In this paper, first static and fatigue tests on four points bending of nomex honeycomb composite sandwich panels have been performed. Load/displacement and S- $N$ fatigue curves are presented and analysed. Fatigue failure and damage modes are observed with an optical microscope and are discussed. The second is to address such fatigue behaviour by using a damage model and check it by experimentation. This fatigue damage model is based on stiffness degradation, which is used as a damage indicator. Two nonlinear cumulative damage models derived from the chosen stiffness degradation equation are examined with assumption of linear Miner's damage summation. Predicted results are compared with available experimental data.

Keywords: Nomex, Sandwich, Stiffness, Failure modes, Fatigue Model.
\end{abstract}

\section{Introduction}

Sandwich composites are widely employed in modern mechanical design, not only in the field of aeronautical constructions, where they have initially been developed, but also in the fields of land transports and marine constructions. Because of their main features, such as the high flexural resistance and stiffness [1], the high impact strength and the high corrosion resistance and the low thermal and acoustics conductivity [2], sandwich structures are in fact preferred over conventional materials in various industrial applications. Although large numbers of research projects have been performed by various authors, the design of structural elements made from sandwich composites is often a difficult task. This is mainly because a reliable strength prediction needs the preliminary knowledge of the mechanical behaviour of skins and core, as well as of the peculiar damage mechanisms [3] and [4] and failure criteria that can be used under a complex loading. From phenomenological point of view, fatigue damage can be evaluated, in the global sense by stiffness, residual strength or other mechanical properties. Fatigue modulus concept for fatigue life prediction of composite materials is proposed by [6]. It is suggested that the changes in stiffness might be an appropriate measure of fatigue damage. Many investigators have examined the effectiveness of the stiffness degradation in composite materials as a measure of accumulated damage [5]. As residual strength, stiffness and life are affected by fatigue damage, only residual stiffness can be monitored non-destructively [7]. Residual strength decreases slowly with the increase of the number of cycles until a stage close to the end of life of the specimen, where it begins to change rapidly until complete destruction [8]. On the contrary, stiffness exhibits greater changes during fatigue specifically at the early stage of fatigue life of specimen [9]. Much important work on residual stiffness has been done by [8]. The residual stiffness as a parameter to describe the degradation behaviour and to predict the fatigue life is selected by [10]. There is an interesting feature in stiffness degradation approach that only limited amount of data is needed for obtaining reasonable results [11] reports that the reduction of bending strength of foam cored sandwich specimen is caused by the stiffness reduction of foam due to ageing of polyurethane foam during fatigue cycles. [12] investigate the static and flexural fatigue characteristics of foam core polymer composite sandwich beams. Failure modes relate to both core shear and skin failure. The results of the stiffness degradation correlated well with the mechanical properties of the sandwich panels. The aim of this study is to develop analytical models describing the flexural behaviour of sandwich composite panels under cyclic fatigue. The stiffness degradation approach allows the assessment of the fatigue damage. Two non-linear cumulative damage models derived from the chosen stiffness degradation equations are examined assuming linear Miner's damage summation. Predicted results are compared to the available experimental data.

\section{Fatigue Modelling}

\subsection{General}

Considering the complexity of failure mechanisms in sandwich composites under fatigue, the necessity for developing more simple models with fewer limitations is quite obvious. The residual stiffness is a parameter that can be monitored nondestructively, and therefore can be related to residual strength and fatigue life of the specimen. However, a comprehensive data base would be required in the fatigue analysis of sandwich composites, based on stiffness reduction, unless mathematical relationships can be developed to relate the residual stiffness to other readily material properties. If such a relationship could be established, extrapolation of data at various stress levels would be derived, thus the amount of test 
data needed to characterize the materials behaviour [13]. The modelling of the fatigue behaviour of composite material during three point bending tests has been proposed by different studies [14]-[15]. These are based on the fatigue modulus reduction of laminate composites and of the sandwich composites. The fatigue modulus which is generally referred as stiffness can be defined as being the ratio between the applied stress and the strain at a given number of cycles [14]. This modulus is function of loading cycles $N$ and applied stress level $r$. The rate of decrease of fatigue modulus can be related to an empirical power function of number of fatigue cycles [16]. The theoretical decrease in shear modulus from an initial static value can be expressed as:

$$
G_{f}(N)=G_{0}-A N^{C}
$$

Where $\mathrm{A}$ and $\mathrm{C}$ are the material constants.

Clark et al., [16] modified this equation using shear modulus concept and suggested that exponential function can be effectively used instead of power function. They developed analytical expression which can be written as:

$$
\begin{gathered}
G_{f}(N)=G_{0} \text { for } N \leq N_{i f}, \\
G_{f}(N)=G_{0}-A e^{\left(N-N_{i f}\right) C} \text { for } N \geq N_{i f}
\end{gathered}
$$

Where $N_{i f}$ is the number of cycles to initiate damage.

The equation used by Clark et al. [16] to predict the number of cycles at failure for different applied stress level, $r$ was given by:

$$
N_{f}=N_{i f}+\frac{\ln [\mathrm{B}(1-\mathrm{r})]}{\mathrm{C}}
$$

Where $B=\frac{G_{0}}{A}, r$ is equal to the ratio of applied stress to ultimate static stress, $\left(r=\frac{\tau_{a}}{\tau_{u}}\right)$, and $N_{f}$ is the number of cycles at failure.

\subsection{Cumulative Damage Equations}

Different forms of the cumulative damage parameter, D, can be chosen depending on the degree of linearity of the degradation response. Three models are investigated. The first model is linear, based on "number of cycles", the second based on changes of "fatigue modulus", whilst the third proposed by us is based on "number of cycles".

Damage is assumed to initiate when fatigue damage is first observed, i.e. at $N=N_{i f}$. At $N=N_{f}$ the damage equal one. For the purpose of all the cumulative damage models investigated, it is assumed that:

$$
\begin{gathered}
D(N)=0 \text { where } N \leq N_{\text {if }} \text { Or } 0 \leq D(N) \leq 1 \\
\text { where } N_{i f} \leq N \leq N_{f}
\end{gathered}
$$

Model I: the most basic linear cumulative damage model is that proposed by [17], which was originally derived from energy consideration. It states that the amount of damage at a given number of cycles is the ratio of the current cycle number to the number of cycles causing fatigue failure. In this case, the damage model occurs after the initiation of damage and can be expressed as:

$$
D(N)=\frac{\left(N-N_{i f}\right)}{\left(N_{f}-N_{i f}\right)} \text { where } N \geq N_{i f}
$$

Model II: the damage function is defined in terms of the fatigue modulus as:

$$
D(N)=\frac{G_{0}-G_{f}(N)}{G_{0}-G_{f}\left(N_{f}\right)}
$$

By manipulation of Eq. (2), equation (6) becomes:

$$
D(N)=\frac{e^{\left(N-N_{i f}\right) C}}{e^{\left(N_{f}-N_{i f}\right) C}} \text { where } N \geq N_{i f}
$$

In this work, the model given by (Eq.6) is used to check its validity in sandwich honeycomb core for both direction of cells ( $\mathrm{L}$ and $\mathrm{W}$ ).

Model III: the damage model takes into account the initiation of damage and the damage is expressed as [18]:

$$
\begin{gathered}
D(N)=\frac{k \beta^{l}}{(k+1)-\beta^{m}} \text { where } N \geq N_{i f}, \\
\beta=\frac{N-N_{i f}}{N_{f}-N_{i f}}, \mathrm{k}, \text { land } \mathrm{m} \text { are the material constants }
\end{gathered}
$$

\section{Materials and Experimental Method}

\subsection{Materials specimen}

The honeycomb sandwich panels used in this study (Figure 1) have been provided by Euro-Composites S.A. (Luxembourg) and are intended for the aircraft industry. The sandwich panels are made from Nomex (aramid fiber) honeycomb core and pure aluminium $\left(\mathrm{AlMg}_{3}\right)$ face sheet. The honeycomb core is an opened cell with various densities of 48, 80, 128 and 144 $\mathrm{kg} / \mathrm{m}^{3}$. The geometrical dimensions of the specimen are shown in Table 1. The mechanical properties of the sandwich panels are depicted in Tables 2.

\subsection{Experimental Method}

Both static and fatigue tests were carried out through a fourpoint bending testing fixture device schematically shown in Figure 2. Static and fatigue tests were carried out in a servohydraulic Instron model 8800 testing machine with $10 \mathrm{kN}$ capacity of loading cell (Figure 3). The INSTRON electronic unit performs the test control and the data acquisition. Static tests were carried out on all configurations samples, using a loading rate of $2 \mathrm{~mm} / \mathrm{min}$, according to the military standards: MIL-STD-401 DIN53291.

Cyclic flexural tests were performed on a minimum of three replicate sandwich beams of the same dimension as in static tests. The tests were achieved under load control at a load ratio $\mathrm{R}=0.1$ using a sinusoidal wave form. The beams were cycled at frequencies of $2 \mathrm{~Hz}$. Fatigue data were generated at load levels of $100 \%, 90 \%, 80 \%, 70 \%$ and $60 \%$ of the static ultimate load. The fatigue life of the specimens is characterized as the number of cycles to ultimate failure. The normalised applied load is plotted against the number of cycles on log-log scale. 


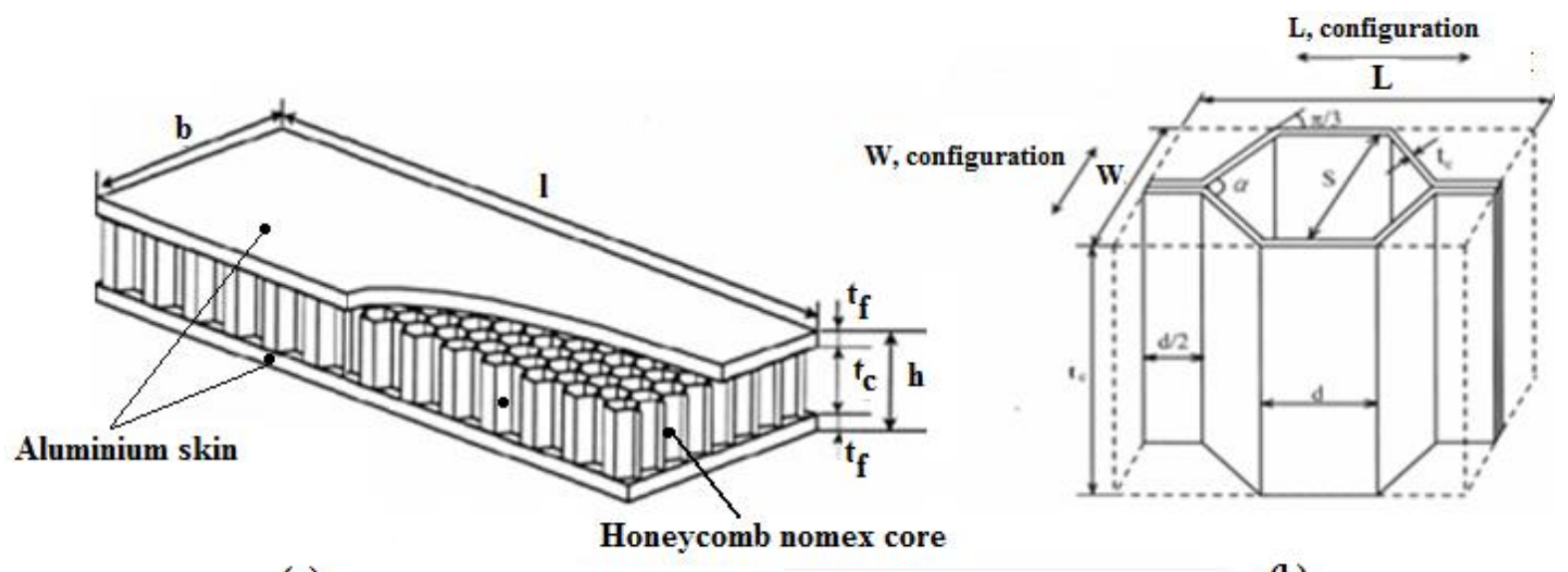

(a)

(b)

Figure 1. Description of the honeycomb sandwich structure and Cells configuration (L and W).

Table 1: Dimensions of specimen.

\begin{tabular}{cccccccc}
\hline $\begin{array}{c}\mathrm{L} \\
(\mathrm{mm})\end{array}$ & $\begin{array}{c}\mathrm{b} \\
(\mathrm{mm})\end{array}$ & $\begin{array}{c}\mathrm{h} \\
(\mathrm{mm})\end{array}$ & $\begin{array}{c}\mathrm{h}_{\mathrm{c}} \\
(\mathrm{mm})\end{array}$ & $\begin{array}{c}\mathrm{t}_{\mathrm{f}} \\
(\mathrm{mm})\end{array}$ & $\begin{array}{c}\mathrm{L}_{2} \\
(\mathrm{~mm})\end{array}$ & $\begin{array}{c}\mathrm{L}_{1} \\
(\mathrm{~mm})\end{array}$ & $\begin{array}{c}\mathrm{d}= \\
\mathrm{h}_{\mathrm{c}}+\mathrm{t}_{\mathrm{f}} \\
(\mathrm{mm})\end{array}$ \\
\hline 500 & 250 & 10 & 8,80 & 0,60 & 420 & 210 & 9,40 \\
\hline
\end{tabular}

Table 2: Mechanical properties of skins.

\begin{tabular}{cccc}
\hline $\begin{array}{c}\text { Young } \\
\text { modulus } \\
{[\mathrm{MPa}]}\end{array}$ & $\begin{array}{c}\text { failure } \\
\text { Strength } \\
{[\mathrm{MPa}]}\end{array}$ & $\begin{array}{c}\text { Tensil Strengh } \\
{[\mathrm{MPa}]}\end{array}$ & $\begin{array}{c}\text { Maxi strain } \\
(\%)\end{array}$ \\
\hline 70000 & 268 & 367 & 13 \\
\hline
\end{tabular}

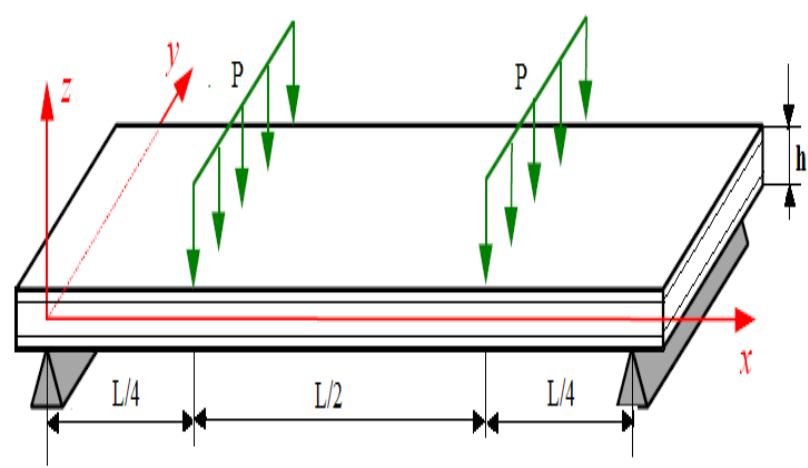

Figure 2. Sketch of the four point bending test.

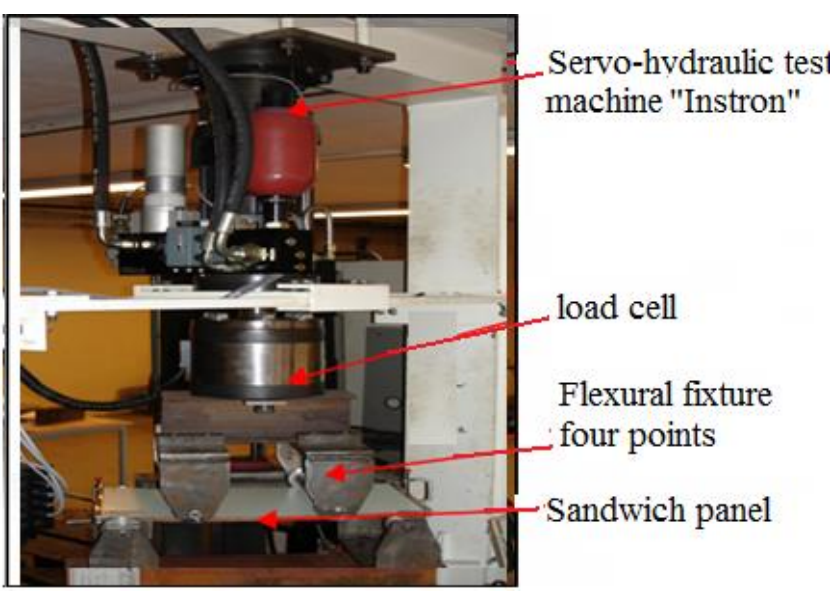

Figure 3. Four point bending experimental setup.

\section{Results and Discussion}

\subsection{Static Tests Results}

Typical maximum load-deflection curves are shown in Figure 4 . The analysis of the experiment results of the static four point bending tests permit to make the following statements (Figure 5 and Figure 6). The sandwich composite stiffness increases when the core density and the maximum load increases with increasing cores densities; the maximum loads and stiffness are higher in the L cells direction than in the $\mathrm{W}$ cells direction, and the maximum bending defection is higher in L cells orientation than in the $\mathrm{W}$ for all core densities. It was observed that the sandwich structures with high core densities present a maximum ultimate load and exhibit ductile behavior as compared to sandwich structures with low core densities.

\subsection{Fatigue Test Results}

To investigate the effect of cell direction on fatigue life, flexural tests were performed on both cell directions ( $\mathrm{L}$ and $\mathrm{W}$ ) of aluminium-Nomex sandwich panel with 48 $\mathrm{kg} / \mathrm{m}^{3}$ core density. Results depicted in Figure 7 show that the fatigue life limit is the same and equals $60 \%$ of the applied load for both directions. Moreover, the material shows more resistance in $\mathrm{L}$ than in $\mathrm{W}$ cells orientation. Indeed, for an applied load of $100 \%$ of ultimate static load the number of cycles for failure is about $10^{2}$ cycles for $\mathrm{W}$ direction, while it is greater and close to $10^{4}$ cycles for $\mathrm{L}$ direction.

The fatigue failure mode for the panel sandwich was core shear cracking in both directions (W and $\mathrm{L}$ ) and the damage during fatigue is visible, as in Figure 8. The localisation of damage in all cases was in the region close to the support where the shear stress is a maximum and constant between the support and the adjacent load application point. The failure propagation is always in the diagonal direction in the case of the L configuration and horizontal for the $\mathrm{W}$.

\section{Application of Models}

In practice, it has been observed that the initiation of fatigue damage occurs where the rate of deflection versus number of cycles response just starts to increase near final failure of the beam for both directions L and W. The Figure 9 presents the displacement (deflection) evolution according to the number of cycles during fatigue cyclic test in load control at different loading levels $r$. 

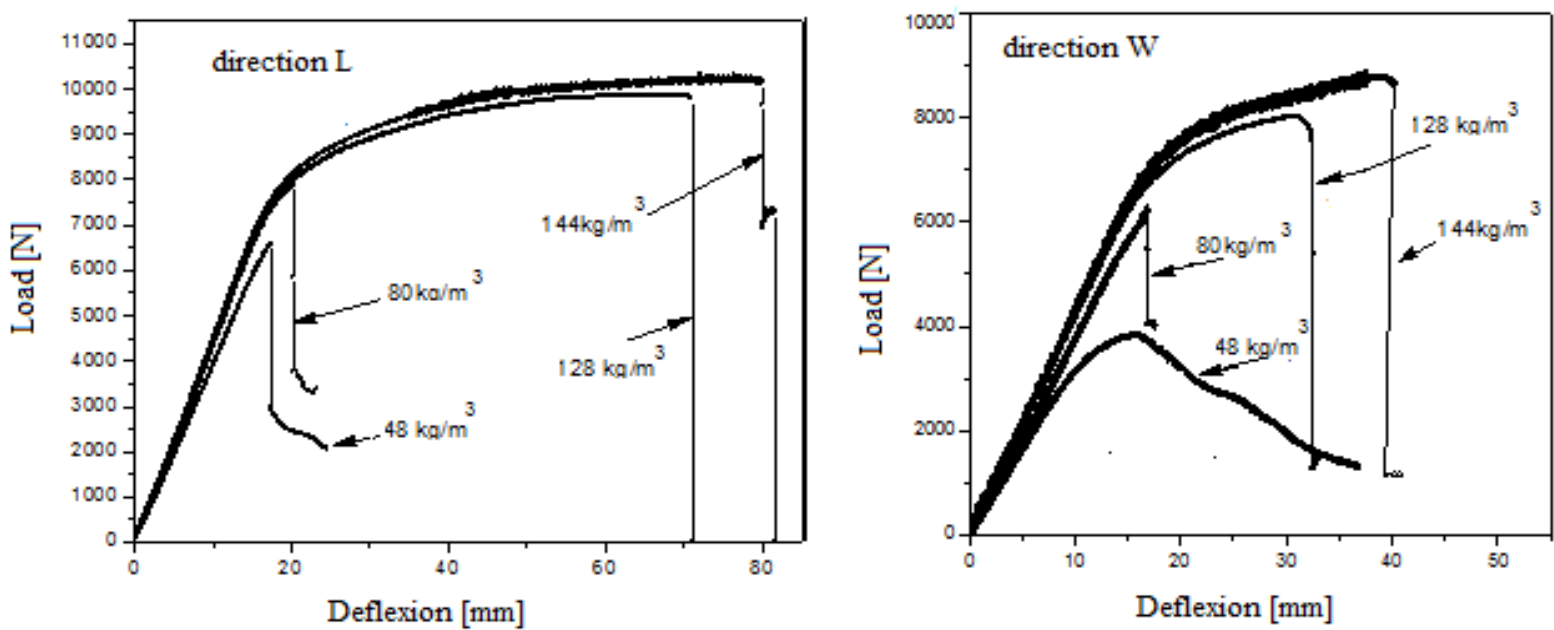

Figure 4. Load/deflection curve for both cell directions (L and W) of Nomex honeycomb sandwich panel.

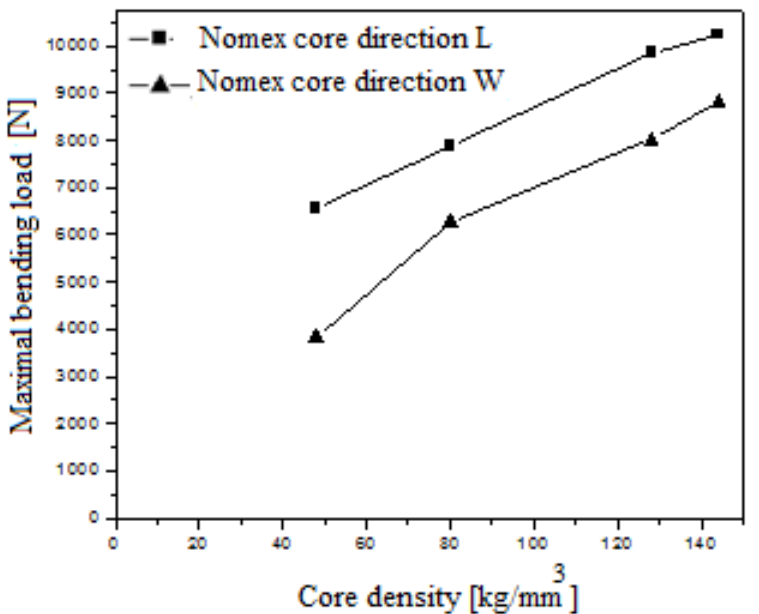

Figure 5. Maximal bending load versus core density.

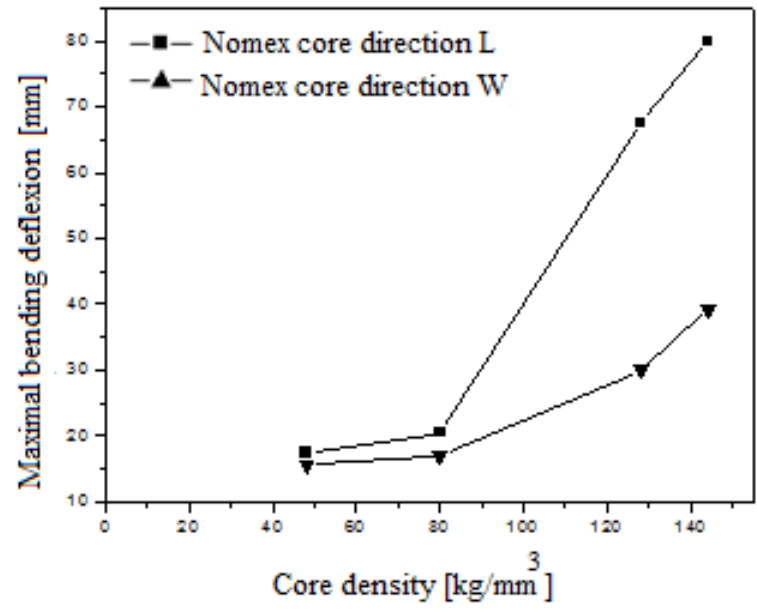

Figure 6. Bending deflection versus core density.
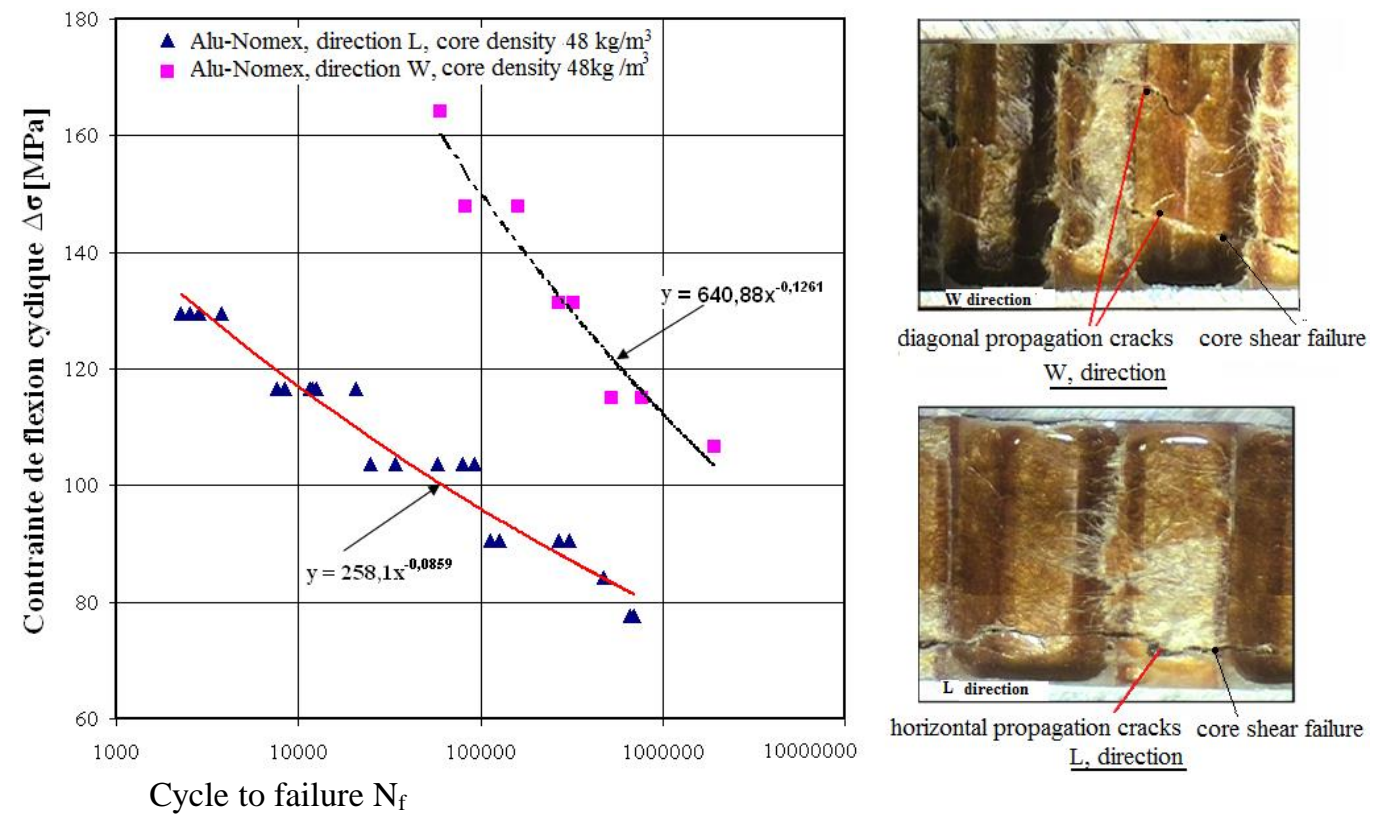

Figure 8. Failure modes of the nomex of cores in the $\mathrm{W}$ and L-

Figure 7. Log-log representation of S-N fatigue curve nomex sandwich in the $\mathrm{W}$ and $\mathrm{L}$ directions. directions. 


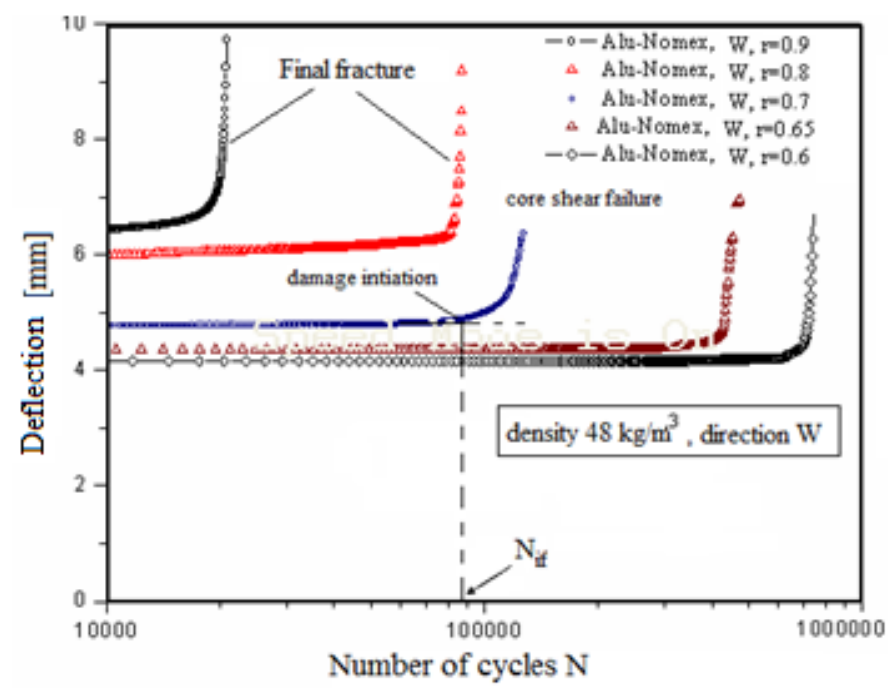

Figure 9. Deflection evolution (Stiffness reduction) according to the number of cycles for different loading level.

\subsection{Degradation Shear Fatigue Modulus}

To compare the theoretical stiffness degradation models ( $\mathrm{L}$ and $\mathrm{W}$ ) with experimental results, it is important to reproduce the overall deflection data into a change in stiffness. The fatigue results of a sandwich, where core shear is the observed failure mode, can be treated solely by the change in core shear modulus with number of cycles [16].

These curves, (Figure 10)) show, first that the core shear modulus remain unchanged and equal to the static modulus until the initiation of fatigue damage (zone 1) for both direction (L and $\mathrm{W}$ ). Second, it rapidly decreases in a short number of cycles until failure (zone 2). At lower load levels, the rate of decrease of the fatigue modulus increases as function of number of cycles.

To determine the experimental parameters $\mathrm{A}$ and $\mathrm{C}$ of the stiffness degradation models (Eq. 2) for both direction (L and $W$ ), experimental modulus degradation curves of the secondary region (zone 2), are plotted as a modulus decrease versus number of cycles. Because the fatigue damage occurs,

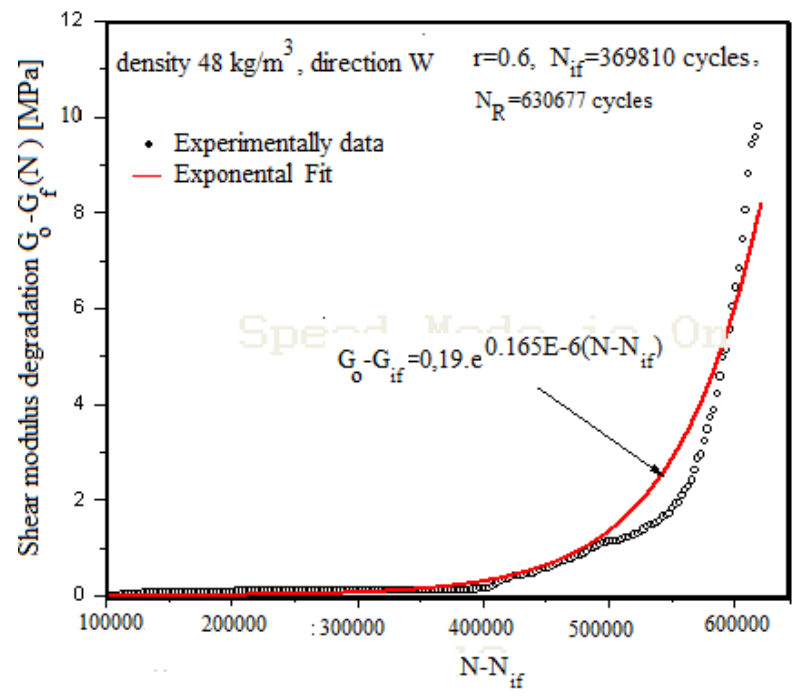

Figure. 11. Exponential fit to fatigue modulus degradation Curve for $\mathrm{W}$ direction

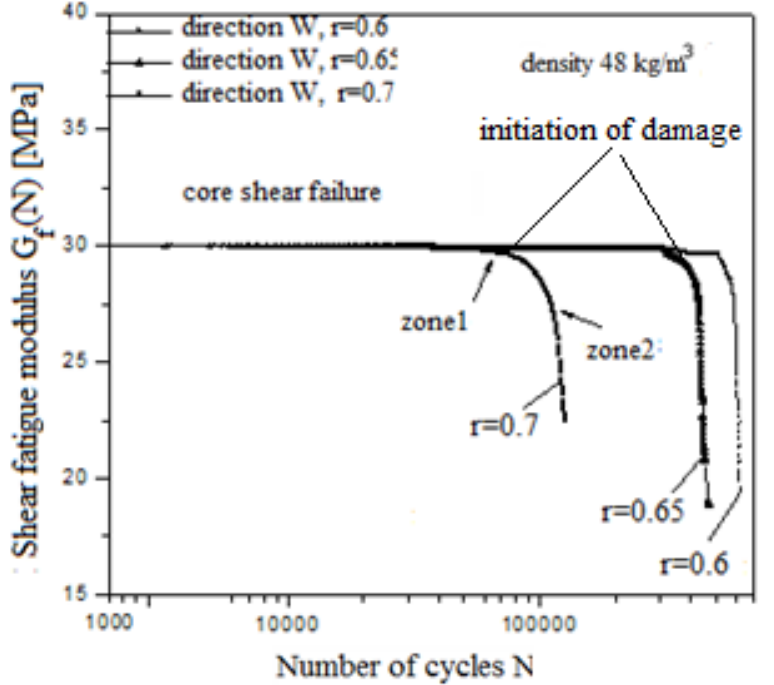

Figure 10. Shear Fatigue modulus degradation curves according to $\mathrm{N}$ cycles for different level $\mathrm{r}$.

in the secondary region, after the initiation of fatigue damage, the number of cycles, for the purpose of fitting the parameters, is given by $\left(\mathrm{N}-\mathrm{N}_{\mathrm{if}}\right)$. The exponential equation used to determine the parameters is:

$$
G_{f}\left(N-N_{i f}\right)=G_{0}-A e^{\left(N-N_{i f}\right) C}
$$

An example of this method is shown in Figure 11 for $\mathrm{W}$ direction.

\subsection{Cumulative Damage Curves}

The three different cumulative damage curves obtained from Eqs. (5), (6), and (8) for direction $\mathrm{W}$ for two load levels are represented in Figure 12. It is observed that the first model (Miner's rule) is linear as expected. While, the models based on fatigue modulus for direction $\mathrm{W}$ are non-linear and exhibit the same behaviour with damage initiation between 0 to 0.3 of normalized life.

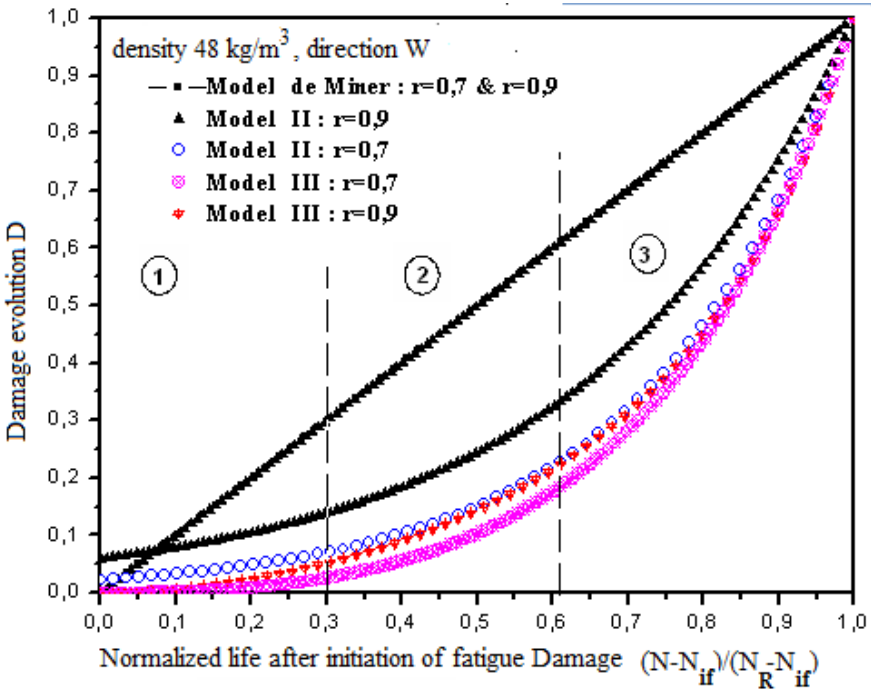

Figure 12. Cumulative damage models for W. 


\section{Conclusion}

Static and Fatigue tests in four points bending were performed on Nomex (fiber aramid) core of sandwich structure for both directions ( $\mathrm{W}$ and $\mathrm{L}$ ). The effect of densities in the case of static study and the effect of cell orientation (L and $\mathrm{W}$ ) of honeycomb core sandwich panels have been investigated. For static study, it was observed that the sandwich structures with high core densities present a maximum ultimate load and exhibit ductile behaviour as compared to sandwich structures with low densities. For fatigue study, the fatigue life limit is the same and equals $60 \%$ of the applied load for both directions; the material shows more resistance and larger life in direction $\mathrm{L}$ than $\mathrm{W}$. The application of the exponential model gave a good result when the cells are in $\mathrm{W}$ direction.

\section{References}

[1] J.R. Vinson, "The behaviour of sandwich structures of isotropic and composite materials", Technomic Publishing Company, 1999.

[2] S. Belouettar, A. Abbadi, Z. Azari, "Experimental Investigation of static and fatigue behaviour of composites honeycomb materials using four point bending tests", Composite Structures, Vol. 87, Issue 3, 265-273, 2009.

[3] C.A. Steeves and N.A. Fleck, "Collapse mechanisms of sandwich beams with composite faces and a foam core, loaded in three-point bending". Part I: International Journal of Mechanical Sciences, Vol. 46, 561-583, 2004.

[4] V. Crupi, G. Epasto, E. Guglielmino, "Collapse modes in aluminium honeycomb sandwich panels under bending and impact loading". International Journal of Impact Engineering, vol.43, 6-15, 2012.

[5] HA. Whitworth "A stiffness degradation model for composite laminates under fatigue loading", Composite Structure, Vol. 40, 95-101, 1997.

[6] W. Hwang, KS. Han, "Fatigue of Composites-Fatigue Modulus Concept and Life Prediction", Journal of Composite Materials March Vol. 20, 154-165, 1986.
[7] HA. Whitworth, "Evaluation of residual strength degradation in composite laminates under fatigue loading". Composite Structure, Vol. 48, 261-264, 2000.

[8] KL. Reifsnider, C. Scott and D. Jermy. "The mechanics of composite strength evaluation", Composites Science and Technology, Vol. 60, Issues 12-13, 2539-2546, 2000.

[9] A. Abbadi, B, Z. Azari, S. Belouettar, J. Gilgert, "Modelling the fatigue behaviour of composites honeycomb Materials using four point bending tests", International Journal of Fatigue, Vol. 32, 1739-1747, 2010.

[10] Wen-Fang. Wu, LJ. Lee and ST. Choi, "A study of fatigue damage and fatigue life of composites laminates", Journal of Composite Materials, Vol. 30, 123-137, 1996.

[11] J. H. Kim, Y. Shin Lee,B. Jun Park, "Evaluation of durability and strength of stitched foam core sandwich structures", Composite Structure. Vol. 47, 543-550, 1999.

[12] RA. Shenoi, SD. Clark and HG. Allen, "Fatigue behaviour of polymer composite sandwich beams", Journal of Composite Materials, Vol. 29, 2423-2445. 1995.

[13] A. El Mahi, M. Khawar Farooq, S. Sahraoui, A. Bezazi, "Modelling the flexural behaviour of sandwich composite materials under cyclic fatigue". Materials and Design, Vol. 25, 199-208, 2004.

[14] W. Hwang, CS. Lee, HC. Park and KS. Han, "Single and multi-stress level fatigue life prediction of glass-epoxy composites", Journal of advanced materials. Vol.26, n 4, 3-9, 1995.

[15] G. Caprino and G. Giorleo, "Fatigue lifetime of glass fabric/epoxy composites", Compos part A: Applied Science Manufacturing, Vol. 30, 299-304. 1999.

[16] S. D. Clark, R. A. Shenoi and H. G. Allen, "Modelling the fatigue behaviour of sandwich beams under monotonic, 2step and block-loading regimes", Composites science and technology, Vol. 59, 471-486, 1999.

[17] M. Miner, "Cumulative damage in fatigue", Journal of Applied Mechanics Part A, Vol.12, 159-164, 1945.

[18] K. Azouaoui, Z. Azari, G. Pluvinage. "Evaluation of impact fatigue damage in glass/epoxy composite laminate", International Journal of Fatigue 32, 443-452, 2010. 